\title{
Occurrence characteristics and lowest speed limit of subauroral polarization stream (SAPS) observed by the SuperDARN Hokkaido East radar
}

\author{
Hiroki Nagano, Nozomu Nishitani* and Tomoaki Hori
}

\begin{abstract}
We investigate the characteristics of the subauroral polarization stream (SAPS), with focus on the relationship between geomagnetic parameters and occurrence characteristics of SAPS. This study's observations were made using the Super Dual Auroral Radar Network (SuperDARN) Hokkaido East radar, which can observe the Far East region of Russia and has been in operation since 2006. In particular, we identify the lowest limit of SAPS speed, which has not been discussed in previous literature, in order to examine the lowest threshold of electric field able to generate SAPS as a result of magnetosphere-ionosphere (M-I) coupling. In order to conduct a comprehensive investigation of SAPS occurrence characteristics, we analyzed events with wider ranges of velocity and magnetic latitude (MLAT) than those in previous studies. As a result of quantitative estimation, we found two categories of westward flows that were reasonably separated using a speed threshold of 150-200 m/s. For the faster flows above the speed threshold, there is a clear correlation between MLAT and SYM-H geomagnetic index, whereas for the slower flows, there is no such correlation. The faster flows are considered to be SAPS, whereas the slower flows are probably associated with mid-latitude F-region ionospheric irregularities not directly related to storms or substorms. This slowest limit of SAPS gives us a minimum electric field of 7.5-10 mV/m that generates SAPS. However, this field strength is not strong enough to cause frictional heating, which is generally considered to be a crucial mechanism for generating SAPS. This result suggests that frictional heating is not always necessary to generate SAPS.
\end{abstract}

Keywords: SAPS; Subauroral polarization stream; SuperDARN; Hokkaido East radar

\section{Findings Introduction}

Westward rapid plasma flows in the subauroral ionosphere, occurring mainly in the evening to the postmidnight sector, are collectively called "subauroral polarization stream (SAPS)" (Foster and Burke 2002). Foster and Burke (2002) first defined SAPS as broad regions of poleward electric field and westward plasma convection in the subauroral ionosphere. SAPS is a manifestation of magnetosphere-ionosphere (M-I) coupling. SAPS is considered to be generated by a poleward polarization electric field that is generated in the low-conductivity region to maintain a current continuity between region-1 field-aligned current (FAC) and region-2 FAC (Anderson and Hanson 1993). The

\footnotetext{
* Correspondence: nisitani@stelab.nagoya-u.ac.jp

Solar-Terrestrial Environment Laboratory, Nagoya University, Furo-cho, Chikusa-ku, Nagoya 464-8601, Japan
}

polarization electric field can be very strong if low conductivity in the subauroral region enhances feedback processes (Foster and Burke 2002).

Foster and Vo (2002) concluded that as magnetic local time (MLT) progresses from the evening to morning sector, the positions of SAPS move to lower latitude and the speed of SAPS becomes slower, using the Millstone Hill incoherent scatter radar. Furthermore, the positions of SAPS are highly correlated with the Kp geomagnetic index. Wang et al. (2008) obtained the empirical relationship between the positions of SAPS and Dst geomagnetic index observed by the Defense Meteorological Satellite Program (DMSP) satellite. They obtained three different empirical models categorized by the electric conductivity as determined by the solar zenith angle. This relation between the SAPS position and the Dst index was supported by the Super Dual Auroral Radar 
Network (SuperDARN) Hokkaido East radar observation (Kataoka et al. 2009).

It should be noted that previous studies focused on very fast SAPS events and did not discuss the slowest limit of SAPS. The feedback process is considered as an indispensable mechanism for generating SAPS (e.g., Foster and Burke 2002). However, past studies focused on the peak velocity of SAPS for data selection and did not confirm the validity of this mechanism. Knowledge of the slowest limit of SAPS could contribute to the clarification of the minimum electric field that generates SAPS, together with its relationship with the feedback process.

\section{Data analysis}

Figure 1 shows the field of view of the SuperDARN (Greenwald et al. 1995) Hokkaido East radar. It covers $40^{\circ}-80^{\circ}$ magnetic latitude (MLAT) range. This radar can observe much lower latitude regions than the other SuperDARN radars.

A limitation of the SuperDARN radar observation, as well as that of other radars, is that the radar obtains only line-of-sight (LOS) Doppler velocity. Here, we assume that the LOS velocity toward the radar is due to the westward flows and converts LOS velocity to westward velocity with L-shell fitting that converts LOS direction to L-shell direction. This assumption is based on Makarevich et al. (2011), who used the two-dimensional SuperDARN observation and showed that the direction of SAPS is always westward. We also adopted a beam-swinging technique, which applies sine-curve fitting to the multiple-beam data to estimate the direction of the flow for each event, and removed events whose flows are not westward. For the data analyses below, we use the common-time FITACF data of the Hokkaido East radar archived by the Exploration of Energization and Radiation in Geospace-Science Center (ERGSC) (Hori et al. 2013). We checked the events of westward flows including the SAPS using a wide range of background conditions. The criteria for choosing westward flows are as follows: (1) The westward speed is over $10.0 \mathrm{~m} / \mathrm{s}$. (2) The magnetic latitude of the flow region is $40^{\circ}$ to $70^{\circ}$. (3) Echoes identified as ground backscatter using the standard SuperDARN data analysis algorithm (Sundeen et al. 2004) are excluded from the statistical analysis. Kataoka et al. (2009) used the SuperDARN Hokkaido East radar to perform statistical analysis of the SAPS flows, focusing on 2 years of data for the range of $45^{\circ}$ to $65^{\circ}$ and peak velocity of over $1 \mathrm{~km} / \mathrm{s}$. The criteria of Foster and Vo (2002) used a latitudinal range of $45^{\circ}$ to $70^{\circ}$ and peak velocity of $500-1000 \mathrm{~m} / \mathrm{s}$. We determined wider criteria for data selection than previous studies in order to examine whether there is a lowest threshold of SAPS speed.

Next, we distinguished subauroral region flows from auroral oval ones by examining the precipitating energy flux obtained from the total electron detector (TED)

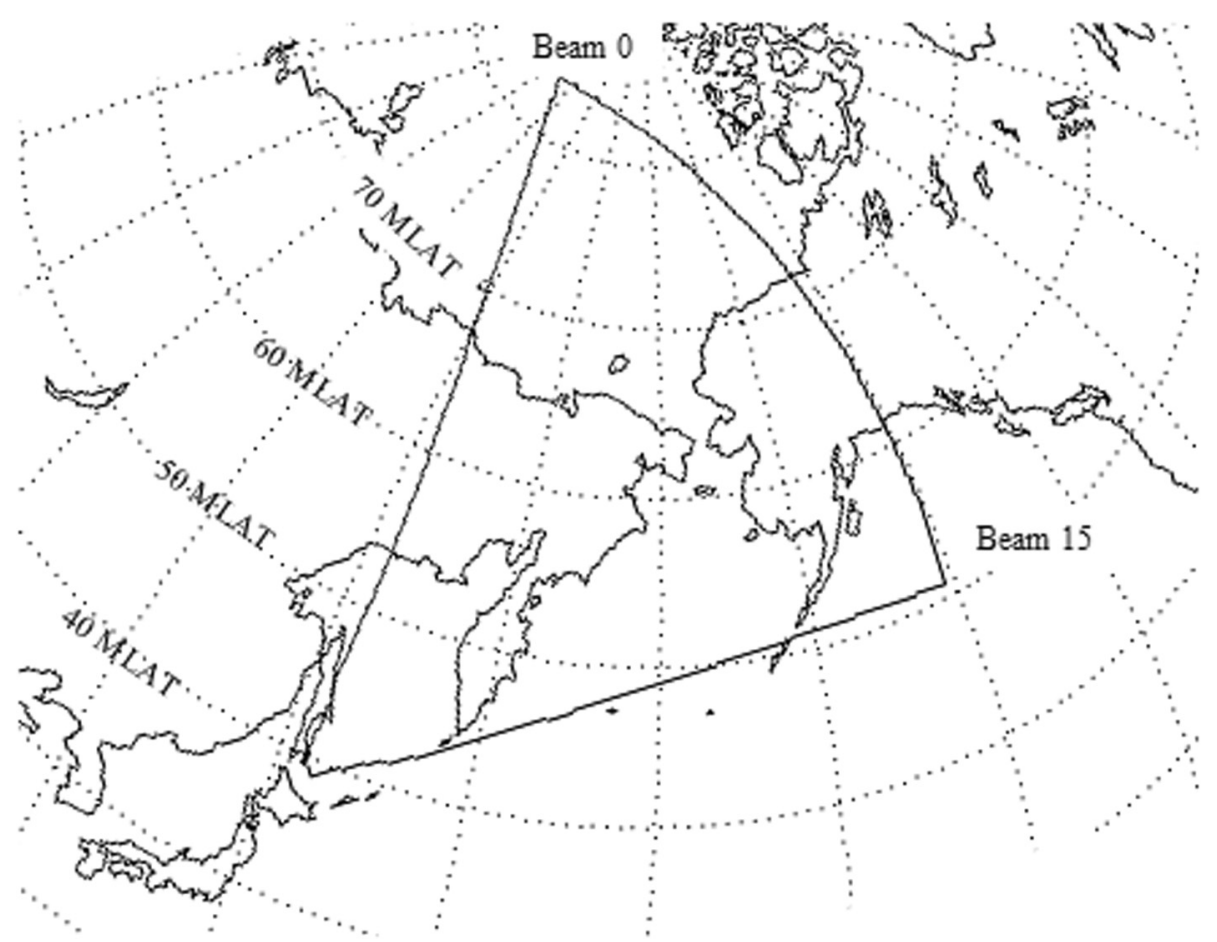

Fig. 1 Field of view of the SuperDARN Hokkaido East radar. The gray grid shows magnetic latitude and longitude in AACGM coordinates 
onboard the National Oceanic and Atmospheric Administration/Polar Orbiting Environmental Satellites (NOAA/ POES). Figure 2 shows one example of the twodimensional distribution of LOS velocities observed by the SuperDARN Hokkaido East radar, as well as the color-coded precipitation energy flux observed by the NOAA 19 satellite data along its footprint going equatorward. The region where precipitation flux is over $10^{0} \mathrm{~mW} / \mathrm{m}^{2}$ is identified as auroral oval, whereas that where the flux is below the value is identified as subauroral region (Yahnin et al. 1997). In this manner, we selected only subauroral region flows. Finally, we obtained the event database of the flow speed together with MLAT, MLT, and SYM-H. SYM-H was obtained instead of the Dst index because we needed higher time resolution of parameters. We sampled the data points every $30 \mathrm{~min}$. Geomagnetic data were obtained from the OMNI database provided by NASA/NSSDC. We utilized this database to investigate the correlation between flow speed and MLAT/SYM-H. From the event-searching process described above, we obtained 839 points of data for 104 days from December 2006 to August 2014.

\section{Result}

In Fig. 3, we show the result of the correlation between MLAT of westward flow and SYM-H. The vertical axis is MLAT of westward flow, and the horizontal axis is SYM-H. Three orange/green/blue curves show the empirical relationship between MLAT and Dst index (Wang et al. 2008). The empirical relationship for high, middle, and low conductivity, categorized by the electric conductivity determined from the solar zenith angle, is shown in orange, green, and blue lines, respectively (for details, refer to Wang et al. 2008). Because the positions of SAPS shift toward lower latitude as MLT progresses (Foster and Vo 2002), the flows are divided into 3-h MLT bins. It is apparent in Fig. 3 that there are two groups each for 16-19 MLT, 19-22 MLT, 22-1 MLT, and 1-4 MLT. One group in each of these panels is well aligned with the empirical curves. The other group, which exists within the region of $40^{\circ}<\mathrm{MLAT}<60^{\circ}$ and $-40 \mathrm{nT}<\mathrm{SYM}-\mathrm{H}<20 \mathrm{nT}$, shows no correlation between MLAT and SYM-H.

From a detailed examination of the dataset, we found that we could separate the two groups by setting the flow speed threshold (details are shown below). We set

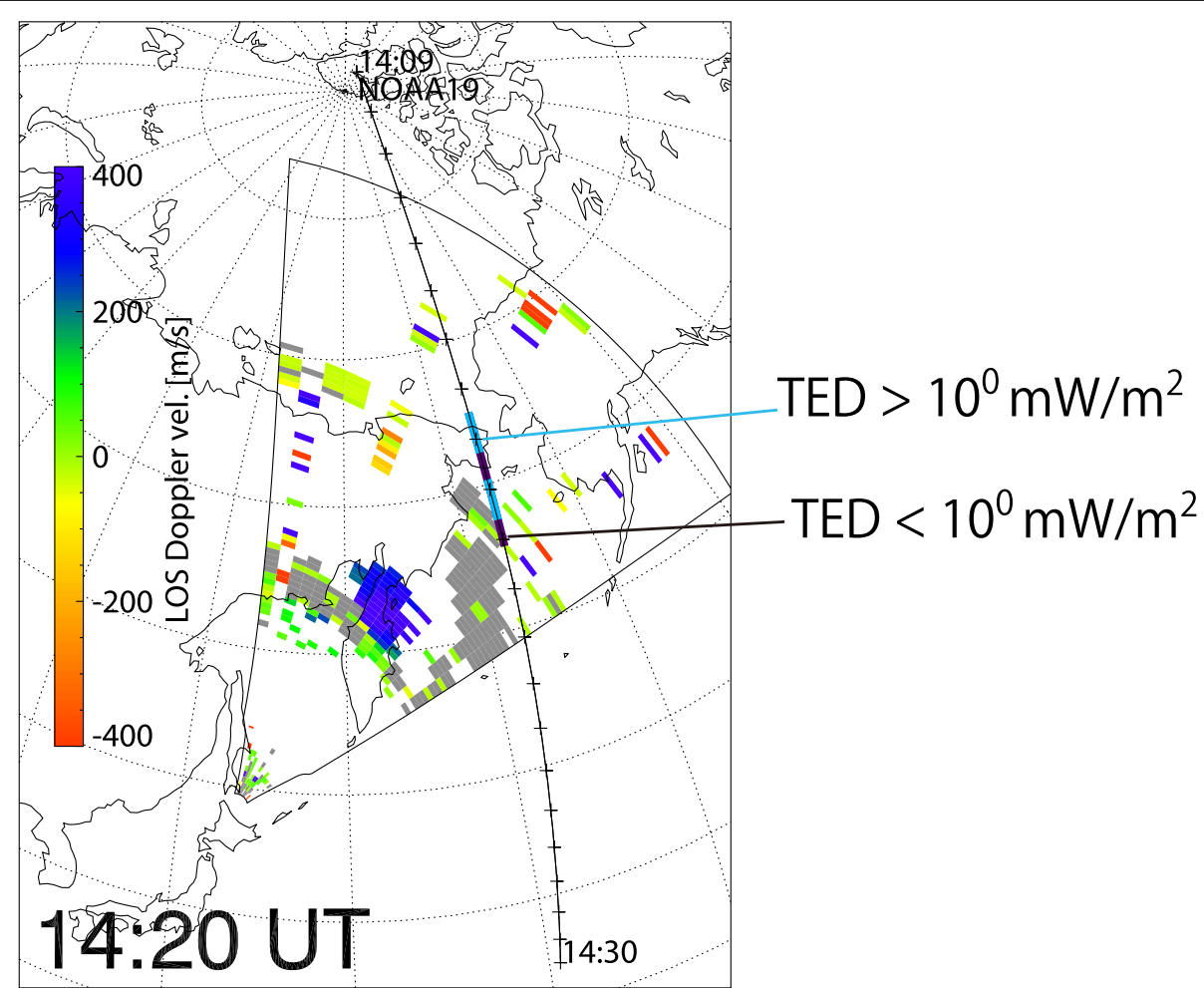

Fig. 2 Example of SuperDARN and NOAA particle data on December 15, 2012. The two-dimensional radar data show LOS velocity at 1420 UT. The color tile shows direction and speed of LOS velocity. The green and blue regions indicate the flows going away from the radar, and the yellow and red regions show flows toward the radar. The NOAA 19 satellite data along its footprint going equatorward show precipitation energy flux for 1400-1430 UT, obtained from TED instrumentation; the aqua color corresponds to flux over $10^{\circ} \mathrm{mW} / \mathrm{m}^{2}$, and the purple color to flux less than $10^{0} \mathrm{~mW} / \mathrm{m}^{2}$. This precipitation flux can distinguish the subauroral region (flux $<10^{0} \mathrm{~mW} / \mathrm{m}^{2}$ ) from the auroral oval (flux $>10^{0} \mathrm{~mW} / \mathrm{m}^{2}$ ) 

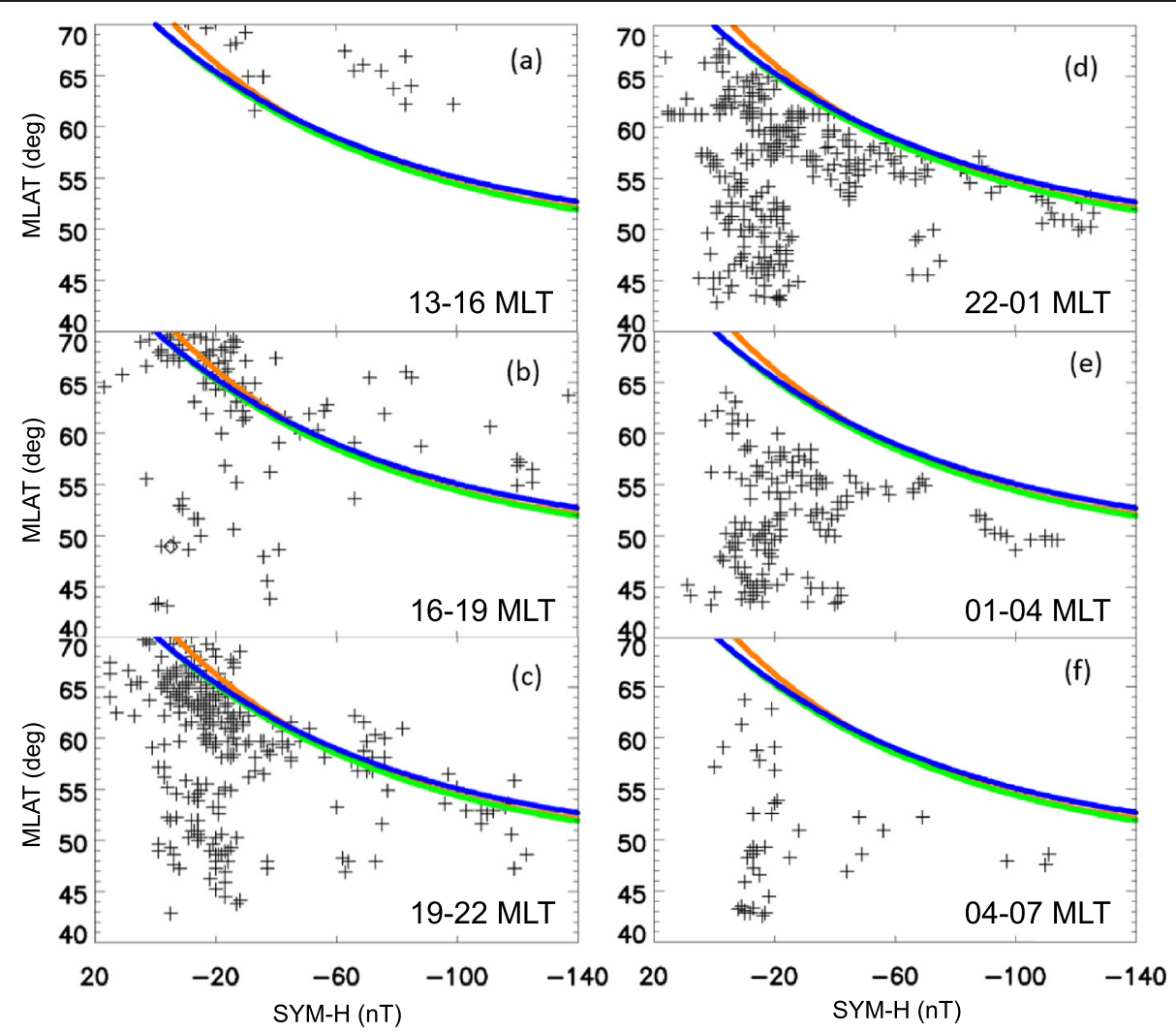

Fig. 3 Relation between westward flow position and SYM-H. The vertical axis is MLAT and the horizontal axis is SYM-H. Three color curves show the empirical relationship between MLAT and Dst index obtained in a previous study (Wang et al. 2008). Each panel is for the 3-h MLT range. a 13-16 MLT, b 16-19 MLT, c 19-22 MLT, d 22-1 MLT, e 1-4 MLT, and f 4-7 MLT

the six speed thresholds from 50 to $300 \mathrm{~m} / \mathrm{s}$ every $50 \mathrm{~m} / \mathrm{s}$ as shown in Fig. 4. In this figure, we show the result of applying these speed thresholds to the 19-22 MLT data, which contains the largest number of events, to investigate the influence of flow speed on the latitude-MLT relationship. From Fig. 4a-f, speed thresholds are 50, 100, 150, 200,250 , and $300 \mathrm{~m} / \mathrm{s}$, respectively. Flows faster than the threshold are plotted with red crosses, whereas flows slower than the threshold are plotted with black squares. When the speed threshold is $50 \mathrm{~m} / \mathrm{s}$, the flows faster than the threshold are scattered, so it is not possible to separate the two groups clearly. However, as the speed threshold rises, the faster flow group is distributed along the empirical curves. As a result, we confirmed that the threshold of $150-200 \mathrm{~m} / \mathrm{s}$ could separate the two groups most effectively.

To confirm that the two groups can be separated by setting the flow speed threshold, speed threshold is further tested using a more quantitative approach. For each MLT bin, we set the latitudinal threshold to divide the flows aligned with the empirical curves from other flows. The black curve in Fig. 5, which crosses $55^{\circ}$ geomagnetic latitude for SYM-H $=-40 \mathrm{nT}$, is used for quantitative estimation as a latitudinal threshold. This latitude is adopted from Foster and Vo (2002) for $\mathrm{Kp}=7$, MLT = 19-22 h. Since it is not easy to identify the precise value of the SYM-H index for $\mathrm{Kp}=7$, we investigated the 3-h negative peak of the 1-h averaged SYM-H for $K \mathrm{p} \geq 7$ during the period of statistical analysis and not associated with sudden commencement (Sc). We found that this negative peak has an upper limit of $-40 \mathrm{nT}$, and we used this value as a reference in determining the threshold curve. In addition, this black curve has the same inclination as the empirical curves. We defined the flows above this black curve to represent SAPS. The latitudinal thresholds for each MLT bin are shown in Table 1. The result of the hypothesis test for each MLT bin is shown in Fig. 6. The vertical axis is the ratio of SAPS (identified as flows above the black curve) among the flows faster than the speed threshold, and the horizontal axis is the speed threshold. The percentage reaches 80-100 \% asymptotically when the speed threshold is over 150 $200 \mathrm{~m} / \mathrm{s}$ except during 4-7 MLT, where there are fewer SAPS flows than other MLTs as already noted in previous studies (e.g., Foster and Vo 2002). This result means that flows faster than $150-200 \mathrm{~m} / \mathrm{s}$ show good 

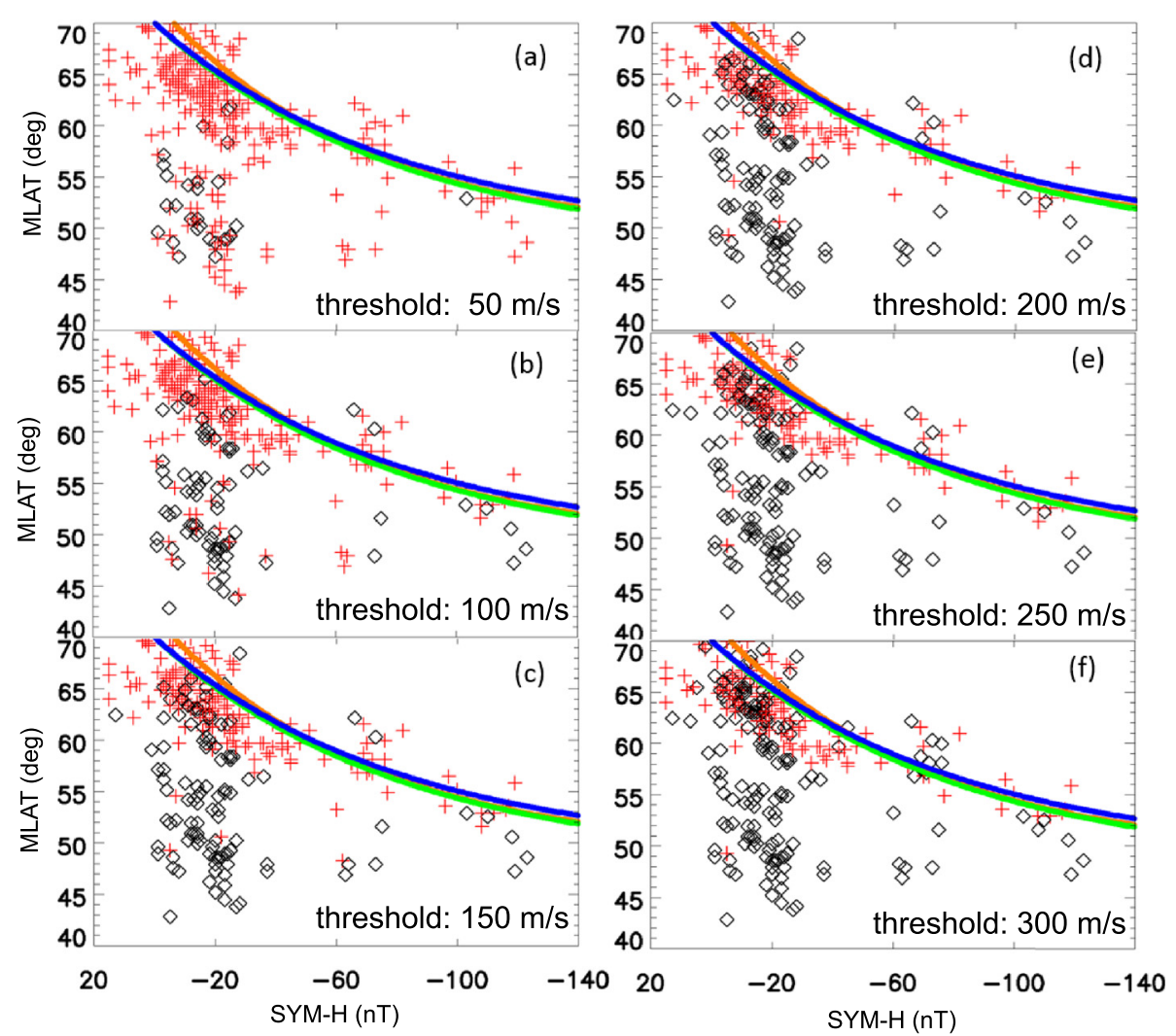

Fig. 4 Result of applying several speed thresholds to $22-1$ MLT data of Fig. 3. Speed thresholds are a 50 m/s, b 100 m/s, c 150 m/s, d 200 m/s, e 250 m/s, and $\mathbf{f} 300 \mathrm{~m} / \mathrm{s}$. Flows faster than the threshold are plotted as red crosses, whereas flows slower than the threshold are plotted as black squares

correlation between SYM-H and MLAT. Therefore, we can identify the slowest limit of SAPS speed as $150-200 \mathrm{~m} / \mathrm{s}$.

\section{Discussion}

We performed a statistical analysis of the westward flows observed by the SuperDARN Hokkaido East radar,

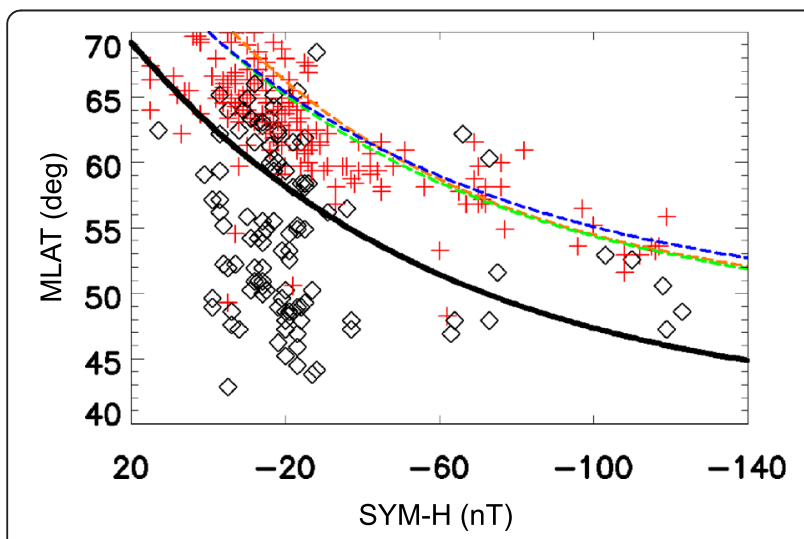

Fig. 5 Similar to Fig. 4, with the black curve used for the test as latitudinal threshold to identify flows as SAPS. For details of determining this curve, please refer to the main text. The other parts are in the same format as Fig. 4c with $150 \mathrm{~m} / \mathrm{s}$ threshold and as a result of the analysis, we found that the lowest limit of SAPS speed is $150-200 \mathrm{~m} / \mathrm{s}$. The strength of the electric field that generates the slowest SAPS is calculated from the equation $\mathbf{v}=\frac{E \times B}{B^{2}}$. Assuming that magnetic flux density $\mathrm{B}$ is $50,000 \mathrm{nT}$, corresponding to the value at about $55^{\circ}$ geomagnetic latitude, the corresponding minimum electric field strength is $7.5-10 \mathrm{mV} / \mathrm{m}$.

Schunk et al. (1975) performed one-dimensional numerical simulation to estimate the ionospheric parameter changes due to frictional heating. They concluded that the electric field should be $50 \mathrm{mV} / \mathrm{m}$ at least in order to cause $\mathrm{O}^{+}$density decrease by $1 / 1.8$. Thus, the minimum SAPS electric field of $7.5-10 \mathrm{mV} / \mathrm{m}$ is not enough to lead to frictional heating that can affect ionospheric plasma-density changes.

Frictional heating is considered as an indispensable mechanism to cause SAPS (Wang and Lühr 2013). Frictional heating raises the recombination rate and reduces

Table 1 Latitudinal threshold of each MLT bin at SYM-H $=-40 \mathrm{nT}$, used for quantitative estimation

\begin{tabular}{lllllll}
\hline MLT [h] & $13-16$ & $16-19$ & $19-22$ & $22-1$ & $1-4$ & $4-7$ \\
MLAT [ $\left.{ }^{\circ}\right]$ & 61 & 58 & 55 & 54 & 52 & 50 \\
\hline
\end{tabular}

For details, please refer to the main text 


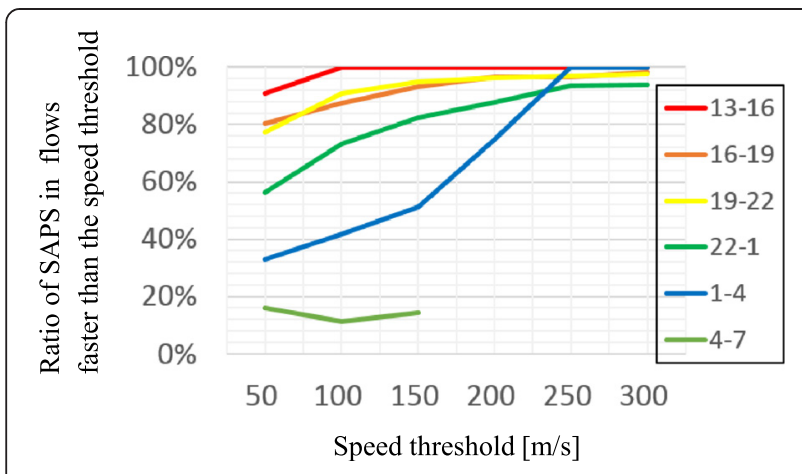

Fig. 6 Result of the test for each MLT bin. The vertical axis is the ratio of SAPS (identified as flows aligned with Wang's curve) in the flows faster than speed threshold. The horizontal axis is the speed threshold. Each color line in the legend represents each MLT range

electron density/conductivity, and then SAPS is generated by the electric field that increases in intensity because of current continuity. However, this small electric field of $7.5-10 \mathrm{mV} / \mathrm{m}$ cannot lead to frictional heating. In other words, frictional heating is not always necessary to generate SAPS in the framework of the coupled largescale magnetosphere-ionosphere system. It should also be noted that frictional heating is indispensable only in the current generator model. Other models are based on other mechanisms of enhancing electric fields. For example, the voltage generator model proposes formation of greater electric fields under constant potential drop and narrower Alfven layer.

Based on several previous statistical studies of the relationship between SAPS latitudinal location and geomagnetic activity, we consider that the flows whose latitude is correlated with the SYM-H or Dst index are SAPS, and those without such correlation are not SAPS. This conclusion is based on the statement of Foster and Burke (2002) that SAPS is considered to be highly related to ring current particles.

It should be mentioned that the SuperDARN radar needs ionospheric irregularities to receive echoes, which are considered to be generated mainly by gradient-drift instability (e.g., Keskinen and Ossakow 1983), growing in intensity if the electric field and plasma density are strong enough and properly oriented. In fact, there is a weak relationship between the SuperDARN echo power and Doppler velocity (Fukumoto et al. 1999; Fukumoto et al. 2000). We therefore examined whether the low speed limit of SAPS is also the low speed limit of SuperDARN observations by checking the echo power around the above limit. The result is that the echo power is mostly 3 to $25 \mathrm{~dB}$, well above the noise level $(0 \mathrm{~dB})$ around the lowest speed limit of SAPS (250 to $300 \mathrm{~m} / \mathrm{s}$ ) (not shown in the figure). Therefore, we can say that the lowest speed limit of SAPS is not the lowest speed limit of SuperDARN observation.

The flows that show no correlation between SYM-H and MLAT are considered to be mid-latitude F-region echoes (Fukao et al. 1988). In order to be sure that these echoes are the mid-latitude F-region echoes, it is necessary to confirm that they have similar characteristics. Fukao et al. (1988) revealed that mid-latitude F-region echoes have spectral width of $20-30 \mathrm{~Hz}$ using the MU VHF radar observation. Since the spectral width is considered to correspond to the decorrelation time of echoes, we need to confirm that our echoes with no SYM-H-latitude relationship have similar parameters. Thus, we checked the spectral width of these echoes converted into the values in the unit of Hertz instead of meters per second. We found that the majority of the echoes have spectral widths less than $40 \mathrm{~Hz}$, which is comparable to the mid-latitude F-region echoes. On the contrary, most of the echoes identified as SAPS (with close SYM-H-latitude relationships) have spectral width wider than $40 \mathrm{~Hz}$, indicating that their characteristics are different from mid-latitude F-region echoes.

\section{Summary}

We investigated the slowest limit of SAPS using the SuperDARN Hokkaido East radar. The flows with westward speed over $150-200 \mathrm{~m} / \mathrm{s}$ show the correlation between SYM-H and MLAT. This tendency has been reported as an established feature of SAPS. On the contrary, flows slower than the threshold do not show this tendency and they are considered to be midlatitude F-region echoes because of their spectral width. Therefore, this lowest speed gives us a minimum electric field that generates SAPS, corresponding to $7.5-10 \mathrm{mV} / \mathrm{m}$. This value suggests that frictional heating is not always necessary to generate SAPS in the framework of the coupled large-scale magnetosphereionosphere system.

In order to perform a more comprehensive statistical study to identify the generation mechanism of SAPS in more detail, we have to analyze more events using other SuperDARN radars covering the subauroral region, such as the Hokkaido West radar that started operations in October 2014.

\section{Competing interests}

The authors declare that they have no competing interests.

\section{Authors' contributions}

HN performed the statistical data analysis and interpretation. NN provided the SuperDARN Hokkaido East radar data and contributed to the data interpretation. TH provided the data analysis software and contributed to the data interpretation. All the authors read and approved the final manuscript.

\section{Acknowledgements}

We would like to thank all the staff who contributed to the HF radar experiment at Hokkaido. We used the OMNI data distributed by NASAV 
NSSDC. The SYM-H was provided by WDC for Geomagnetism, Kyoto. This work was supported by Special Funds for Education and Research (Energy Transport Processes in Geospace) and the Inter-university Upper atmosphere Global Observation Network (IUGONET) project of the Ministry of Education,

Culture, Sports, Science and Technology of Japan.

Received: 31 March 2015 Accepted: 3 August 2015

Published online: 13 August 2015

\section{References}

Anderson P, Hanson W (1993) A proposed production model of rapid subauroral ion drifts and their relationship to substorm evolution. J Geophys Res 98:6069-6078

Foster JC, Burke WJ (2002) SAPS: a new categorization for sub-auroral electric fields. Eos Trans Am Geophys Union 83:393. doi:10.1029/2002EO000289

Foster JC, Vo HB (2002) Average characteristics and activity dependence of the subauroral polarization stream. J Geophys Res 107:1475. doi:10.1029/2002JA009409

Fukao S, McClure JP, Ito A, Sato T, Kimura I, Tsuda T, Kato S (1988) First VHF radar observation of midlatitude F-region field-aligned irregularities. Geophys Res Lett 15:768-771. doi:10.1029/GL015i008p00768

Fukumoto M, Nishitani N, Ogawa T, Sato N, Yamagishi H, Yukimatu AS (1999) Statistical analysis of echo power, Doppler velocity and spectral width obtained with the Syowa South HF radar. Adv Polar Upper Atmos Res 13:37-47

Fukumoto M, Nishitani N, Ogawa T, Sato N, Yamagishi H, Yukimatu AS (2000) Statistical study of Doppler velocity and echo power around 75 deg magnetic latitude obtained with the Syowa East HF radar. Adv Polar Upper Atmos Res 14:93-102

Greenwald RA, Baker KB, Dudeney JR, Pinnock M, Jones TB, Thomas EC, Villain J-P, Cerisier J-C, Senior C, Hanuise C, Hunsucker RD, Sofko G, Koehler J, Nielsen E, Pellinen R, Walker ADM, Sato N, Yamagishi H (1995) DARN/SuperDARN Space Sci Rev 71:761-796. doi:10.1007/BF00751350

Hori T, Nishitani N, Miyoshi Y, Miyashita Y, Seki K, Segawa T, Hosokawa K, Yukimatu AS, Tanaka Y, Sato N, Kunitake M, Nagatsuma T (2013) An integrated analysis platform merging SuperDARN data within the THEMIS tool developed by ERG-Science Center (ERG-SC). Adv Polar Sci 24:69-77. doi:10.3724/SP.J.1085.2013.00069

Kataoka R, Hosokawa K, Nishitani N, Miyoshi Y (2009) SuperDARN Hokkaido radar observation of westward flow enhancement in subauroral latitudes. Ann Geophys 27:1695-1699. doi:10.5194/angeo-27-1695-2009

Keskinen MJ, Ossakow SL (1983) Theories of high-latitude ionospheric irregularities: a review. Radio Sci 18:1077

Makarevich RA, Kellerman AC, Devlin JC, Ye H, Lyons LR, Nishimura Y (2011) SAPS intensification during substorm recovery: a multi-instrument case study. J Geophys Res 116:A11311. doi:10.1029/2011JA016916

Schunk RW, Raitt WJ, Banks PM (1975) Effect of electric fields on the daytime high-latitude E and F regions. J Geophys Res 80:3121-3130. doi:10.1029/JA080i022p03121

Sundeen SR, Blanchard GT, Baker KB (2004) Reanalysis of criteria for identifying ground scatter. In: SuperDARN 2004 Workshop, Saskatoon, Canada

Wang H, Lühr H (2013) Seasonal variation of the ion upflow in the topside ionosphere during SAPS (subauroral polarization stream) periods. Ann Geophys 31:1521-1534. doi:10.5194/angeo-31-1521-2013

Wang H, Ridley AJ, Lühr H, Liemohn MW, Ma SY (2008) Statistical study of the subauroral polarization stream: its dependence on the cross-polar cap potential and subauroral conductance. J Geophys Res 113:A12311. doi:10.1029/2008JA013529

Yahnin AG, Sergeev VA, Gvozdevsky BB, Vennerstrøm S (1997) Magnetospheric source region of discrete auroras inferred from their relationship with isotropy boundaries of energetic particles. Ann Geophys 15:943-958. doi:10.1007/s00585-997-0943-z

\section{Submit your manuscript to a SpringerOpen ${ }^{\odot}$ journal and benefit from:}

- Convenient online submission

- Rigorous peer review

- Immediate publication on acceptance

- Open access: articles freely available online

- High visibility within the field

- Retaining the copyright to your article

Submit your next manuscript at $>$ springeropen.com 